\title{
Hidradenitis Suppurativa and Its Impact on Sleep Quality
}

\author{
Ellen M S Xerfan ${ }^{1}$, Anamaria S Facina ${ }^{2,{ }^{*}}$, Monica L Andersen ${ }^{3}$, Sergio Tufik ${ }^{3}$ and Jane Tomimori ${ }^{2}$ \\ ${ }^{1}$ Programa de Pos-Graduacao em Medicina Translacional, Universidade Federal de Sao Paulo (UNIFESP), Sao Paulo, Brazil \\ ${ }^{2}$ Departamento de Dermatologia, Universidade Federal de Sao Paulo (UNIFESP), Sao Paulo, Brazil \\ ${ }^{3}$ Departamento de Psicobiologia, Universidade Federal de Sao Paulo (UNIFESP), Sao Paulo, Brazil \\ "Corresponding author: Universidade Federal de Sao Paulo (UNIFESP), Sao Paulo, Brazil. Tel: +55-1155764804, Email: dermatologista@hotmail.com
}

Received 2020 April 11; Accepted 2020 April 11.

Keywords: Quality of Life, Sleep, Sleep Disorders, Hidradenitis, Acne Inversa, Sleep Disturbance

\section{Dear Editor,}

Hidradenitis suppurativa (HS), also known as acne inversa, is a chronic inflammatory dermatological disease of the hair follicle that usually begins after puberty. It is manifested by painful, inflamed, and/or abscessed clinical lesions that commonly involve the axillae, inguinal, and anogenital areas (1). It is considered a recurrent, commonly debilitating skin condition that may develop with a high degree of severity and may directly affect the quality of life of affected patients (2). We are writing to highlight an important topic, the relationship between HS and sleep impairment, and how this could affect the quality of life.

Hidradenitis suppurativa is characterized by symptoms such as pain, itching, and putrid smell associated with the infection. It can also result in significant aesthetic disfigurement. All these factors may converge to produce extreme psychological damage to those who have the condition (1), leading to the worsening of sleep and life quality.

The treatment of HS is a challenge in dermatological practice and demands persistence by the patient, especially concerning hidden fistulae lesions that need regular care at home. Despite the variety of options of treatment, there is no single, completely effective, and fast therapy that acts on the fundamental mechanism of the follicular inflammation (2). Cytokine-mediated inflammation is considered the main mechanism in HS pathophysiology, and therefore, immunosuppressive agents have been used for treatment. The TNF $\alpha$ blockers have been reported to be effective in some but not all cases $(2,3)$. An overexpression of various other cytokines such as interleukin (IL)-1beta, IL10 , and IL-11 has also been already described in HS lesions (4). However, there are a few studies of the correlation between sleep and immunological impairment in the con- text of HS and how the interleukin imbalance could be associated with sleep worsening.

The condition can greatly increase stress and anxiety in those affected, which can negatively impact sleep. Herewith, one study reported that HS was associated with a higher incidence of obstructive sleep apnea (OSA). The OSA incidence was also found to be four times higher among obese patients with HS than in a group without HS. The study also found an increased OSA risk in women and younger patients with HS, suggesting that these affected populations must also be frequently monitored for sleep disturbance similarly to patients that present classic risk factors for OSA, such as obese, male, or older patients (5). We suggest that the use of polysomnography is important for monitoring HS patients to better assess their sleep and treat any previously unidentified sleep disturbance.

Another study evaluated the influence of itching and pain on the sleep quality of 108 patients with HS. Through sleep questionnaires such as the Pittsburgh Sleep Quality index (PSQI) and the Athens Insomnia scale (AIS), the study showed that these symptoms had a relevant impact on the frequency of insomnia and sleep quality in patients with HS, compared with controls (6). Another study showed that pruritus affected sleep in more than half of $211 \mathrm{HS}$ patients studied (7).

Thus, given the importance of satisfactory sleep to a good quality of life, we highlight the need for routine application of sleep questionnaires when treating this group of patients. The use of such a simple and effective method of sleep evaluation, as well as further research into the sleep behavior of HS patients and its correlation with their symptoms, could help provide a better understanding of sleep profile in this population and point the way toward new approaches in the care of individuals with HS.

Copyright (c) 2020, Journal of Skin and Stem Cell. This is an open-access article distributed under the terms of the Creative Commons Attribution-NonCommercial 4.0 International License (http://creativecommons.org/licenses/by-nc/4.0/) which permits copy and redistribute the material just in noncommercial usages, provided the original work is properly cited. 


\section{Footnotes}

Authors' Contribution: All authors have contributed equally to the development of this manuscript.

Conflict of Interests: The authors declare that there are no conflicts of interest.

Ethical Approval: All named authors meet the International Committee of Medical Journal Editors (ICMJE) criteria for authorship for this article, take responsibility for the integrity of the work as a whole, and have given their approval for this version to be published.

Funding/Support: Our studies are supported by the Associaçao Fundo de Incentivo a Pesquisa (AFIP). ST and MLA receive CNPq fellowships. EMSX receives CAPES PostGraduation grant. No sponsorship was received for the publication of this manuscript.

\section{References}

1. Zouboulis CC, Desai N, Emtestam L, Hunger RE, Ioannides D, Juhasz I, et al. European S1 guideline for the treatment of hidradenitis sup- purativa/acne inversa. J Eur Acad Dermatol Venereol. 2015;29(4):619-44. doi: 10.1111/jdv.12966. [PubMed: 25640693].

2. Dinarello CA, van der Meer JW. Treating inflammation by blocking interleukin-1 in humans. Semin Immunol. 2013;25(6):469-84. doi: 10.1016/j.smim.2013.10.008. [PubMed: 24275598]. [PubMed Central: PMC3953875].

3. van der Zee HH, Prens EP. Failure of anti-interleukin-1 therapy in severe hidradenitis suppurativa: A case report. Dermatology. 2013;226(2):97-100. doi: 10.1159/000343221. [PubMed: 23713053].

4. van der Zee HH, Laman JD, de Ruiter L, Dik WA, Prens EP. Adalimumab (antitumour necrosis factor-alpha) treatment of hidradenitis suppurativa ameliorates skin inflammation: An in situ and ex vivo study. Br J Dermatol. 2012;166(2):298-305. doi: 10.1111/j.1365-2133.2011.10698.x. [PubMed: 22013960].

5. Wertenteil S, Strunk A, Garg A. Incidence of obstructive sleep apnoea in patients with hidradenitis suppurativa: A retrospective population-based cohort analysis. Br J Dermatol. 2018;179(6):1398-9. doi: 10.1111/bjd.16931. [PubMed: 29957857].

6. Kaaz K, Szepietowski JC, Matusiak L. Influence of itch and pain on sleep quality in patients with hidradenitis suppurativa. Acta Derm Venereol. 2018;98(8):757-61. doi: 10.2340/00015555-2967. [PubMed: 29756157].

7. Vossen A, Schoenmakers A, van Straalen KR, Prens EP, van der Zee HH. Assessing pruritus in hidradenitis suppurativa: A cross-sectional study. Am J Clin Dermatol. 2017;18(5):687-95. doi: 10.1007/s40257-0170280-2. [PubMed: 28429245]. [PubMed Central: PMC5602064]. 